\title{
BERNARD RUDOFSKY: ARCHITECTURE WITHOUT ARCHITECTS, A SHORT INTRODUCTION TO NON-PEDIGREED ARCHITECTURE
} Alburquerque: University of New Mexico Press, 1987. 128 páginas, formato 21,5x24 cms. ISBN: 9780826310040

\section{Mar Loren-Méndez}

Dra. arquitecta. Profesora Titular de Universidad. Departamento de Historia, Teoría y Composición Arquitectónica. Escuela Técnica Superior de Arquitectura. Universidad de Sevilla. España.

Persona de contacto: marloren@us.es

ernard Rudofsky (Moravia, 1905 - Nueva York, 1988) fue un arquitecto polifacético: crítico, editor de revistas como Domus, diseñador de moda y mobiliario, fotográfo, investigador, profesor y comisario de exposiciones. Su trayectoria interdisciplinar alcanza un reconocimiento internacional con la puesta en valor de la arquitectura vernacular, siendo su muestra Arquitectura sin arquitectos, una breve introducción a la arquitectura sin pedigrí en el MoMA de Nueva York su proyecto con mayor proyección. Su catálogo homónimo constituye sin duda una de las publicaciones más citadas en el campo de la arquitectura vernacular, llegando incluso a acuñar el neologismo arquitectura sin arquitectos para referirnos a estas arquitecturas anónimas. La obra de Rudofsky goza hoy de gran reconocimiento, sobre todo entre los arquitectos, aunque queda aún trabajo por hacer en un conocimiento más profundo de esta publicación. Esta reseña pretende aportar luz en torno a sus objetivos y enfoque crítico.

Arthur Dexler, director del Departamento de Arquitectura y Diseño del MoMA, invitó a Rudofsly en 1960 a comisariar un conjunto exposiciones menores fotográficas de carácter pedagógico. Cuatro de estas muestras estaban pensadas únicamente para que itineraran, sin previa exposición en el MoMA de Nueva York: Roads (1961), Stairs (1963), Architecture without architects (1964), y Streets, Arcades and Galleries (1967). Rudofsky sin embargo utiliza el encargo como vehículo creativo para criticar duramente el supuesto progreso del mundo contemporáneo, centrándose en su arquitectura. Desarrolla una valoración de lo vernacular como alternativa de lo Moderno, cuestionando la contribución que el arquitecto como autor tiene en la configuración de nuestro entorno construido.

La fuerza del mensaje rudofskiano provocó que fuera censurada y tachada de subversiva por las instituciones del mundo de la arquitectura en Estados Unidos, que presionaron al MoMA para que la cancelara. Pero ese rechazo no evitó su reconocimiento: la muestra se incluyó en última instancia en el programa expostivo del MoMA de Nueva York y se presentó en diversos países durante más de una década y la publicación fue traducida a múltiples lenguas.

Con un proyecto expositivo que escapa de categorizaciones geográficas o cronológicas -de centros dominantes frente a periferias-, AWA propone una experiencia espacial y visual en la que paisajes diversos y distantes en el espacio y en el tiempo quedan visualmente relacionados por la sabiduría de la tradición. Aby Warburg ya había utilizado en su Bilderatlas esta estrategía comparativa, conectando visualmente la producción artística de diferentes culturas. A través de una organización transversal temática muestra al visitante los valores de lo vernacular, invitándoles a desmantelar el paralelismo asumido entre arquitectura tradicional y el denominado mundo subdesarrollado. Esta arquitectura sin arquitectos pasa, durante la experiencia expositiva de potente carga artística, de ser desconocida por la mayoría de los visitantes a ser valorada, provocando además la actitud crítica.

El catálogo continúa las estrategias de la muestra, en la que prevalece el impacto visual frente a la elaboración histórica y teórica de lo vernacular. La publicación consiste en un solo texto introductorio, acompañado de 156 fotografías, organizadas temáticamente y complementadas por breves comentarios. En 
contraste con la creencia de una utilización generalizada de fotografías del propio Rudofsky, esta publicación sólo incluye 20 fotografías del autor, recogiendo únicamente Grecia, España, Italia, Francia e India, con clara predominancia de los dos primeros.

El texto introductorio se desarrolla en poco más de 1600 palabras, condensando la actitud subversiva de la exposición. Denuncia la parcialidad de la historia de la arquitectura, que se ha reducido a un limitado arco temporal con centro en la producción del poder en Occidente, reivindicando la presencia de toda esta arquitectura vernacular desconocida a nivel internacional. Aclara que mientras en la historia ortodoxa de la arquitectura el énfasis se coloca en la autoría del arquitecto, en su publicación el acento se pone en la empresa colectiva.

La comparación se convierte así en su metodología principal que utilizará de manera consistente y continuada en su obra escrita. Afirma que la serenidad, humanidad e inteligencia de estos asentamientos desconocidos contrasta con la lacra de las construcciones contemporáneas: se refiere concretamente a la arquitectura y la ciudad modernas en Estados Unidos en el período de Posguerra, y en la identificación del progreso con el confort y el consumismo tecnificado del habitar que representa el Sueño Americano.

Su organización temática recorre la implantación urbana en el paisaje -Hill Towns-, la adaptación de la tipología -Unit Architecture- la sofisticación sostenible de las cuevas -Troglodytism-, la ciudad como espacio habitado, prestando atención a sus calles como extensión del espacio doméstico: sus pórticos -Arcades- o sus toldos -Covered Streets. Desmantela así mismo la dimensión funcional, basada únicamente en la utilidad, la "función trascendente" de la experiencia estética del lugar, de su elección y de la implantación aparece en secciones como "The Choice of Place" y "Quasi-sacral architecture". Estas temáticas serían desarrolladas posteriormente por Rudofsky en sus libros Streets for People (1969) y The Prodigious Builders (1977), dedicando además artículos monográficos a muchas de ellas.

Con esta celebración y reivindicación crítica de lugares en todo el mundo, reclama la diversidad como valor esencial de nuestro mundo construido. Rudofsky se desmarca de una apreciación objetual de la arquitectura vernacular; su insistencia en las distintas escalas de la arquitectura que recorren el edificio, la calle, la ciudad y el territorio hacen explícito en su texto la dimensión paisajística de la arquitectura. Estos paisajes por otro lado aparecen habitados, despreciando la tendencia de los supuestos modernos de expulsar al usuario de la arquitectura, incorporando constantemente sus valores intangibles, que transitan desde la actividad productiva, la interacción en comunidad o las aspiraciones espirituales de nuestras formas de vida.

En contraste con las aspiraciones de los estudios vernaculares desde otras disciplinas como la Antropología, Rudofsky aclara la necesidad de incorporar lo aprendido de estas arquitecturas anónimas a la arquitectura contemporánea. Esta publicación nos recuerda en última instancia la fuerza revulsiva que puede alcanzar un libro de arquitectura como arma poderosa en la mejora de nuestro mundo construido. 